\section{No loss of clarity}

The I-Max digital panoramic unit, available exclusively in the UK from Imaging Technologies can be used for panoramic radiographs of adults as well as children and is useful to X-ray the sinuses.

Fully integrated with Quick Vision software, the I-Max is simple to operate, offering effective diagnoses based on digital technology and Owandy image processing. With the image being digitised at source, loss of clarity is eliminated as is the problem of information becoming altered or damaged.

Sharing resources with I-Max is simple regardless of your current configuration. The USB 2.0 interface of the I-Max can be easily connected to any PC with a USB port. The I-Max Easy is supplied with a compact flash card that can be used to store images without a PC connection. The removable card can then be taken to any other PC in the practice or off the premises.

You may zoom in or out, reverse video or view pseudo-colours and the Quick Vision software can manipulate the image in ways that help you better understand the patient's pathology. Going digital will cut out developing costs and associated pollutants, and free up the space previously occupied by the darkroom.

Reader response number 51

\section{Easy trimming}

Aquasil Bite impression material from Dentsply is designed for accurate interoc-

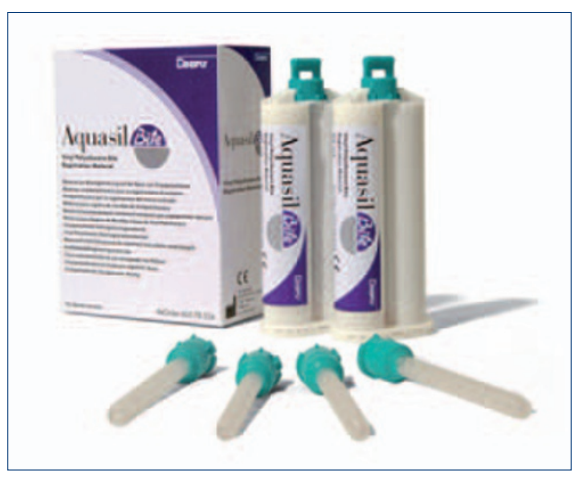

\section{Magnetic oral irrigator}

The Hydrofloss Kitty Waterjet can be effective in helping patients remove bacteria that brushing and flossing cannot. A magnetic device has been added to the unit and this makes it twice as effective as an unmagnetised irrigator. In the last 12 months the Hydrofloss unit and packaging has been upgraded and redesigned to be more attractive to patients.

You can place an order for each unit needed and the unit is shipped direct to your patient, you can accrue credits for stock each time one of your patients orders a unit through the firm's coded order system or you can recommend the unit and receive cash. The company can

\section{Cordless ease with speed}

Dentsply has recently launched the third, Blue Sky version of the SmartLite PS, in addition to the existing Sunset version and Original versions. The product offers high performance with short curing times.

The SmartLite PS can be used for cordless ease, curing speed and quality; it has a 'zero footprint' size, is portable and is low maintenance. On purchase of Smart-

clusal and jaw relation records, and combines high final hardness with resistance to breaking. Trimming is easy because of its A-silicone technology.

It offers minimum resistance to closure during working time and produces consistently accurate jaw relation records. Good detail reproduction and low linear dimensional changes make Aquasil Bite a high precision material. The combination of sufficient working time and short setting time ensures dentist and patient comfort. The product is available in a convenient $50 \mathrm{ml}$ cartridge delivery system and Aquasil Bite conturation tips are offered as an accessory.

Reader response number 53

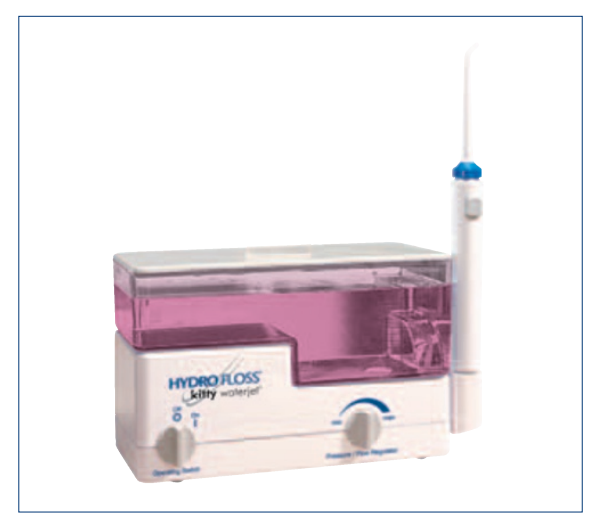

also supply the units direct to you in cases of six for $£ 54+$ VAT per unit (RRP £89.99).

Reader response number 50

Lite PS, send a copy of your invoice to get 60 compules of Spectrum $\mathrm{TPH}^{3}$ or one starter kit of Ceram.X duo free. Reader response number 52

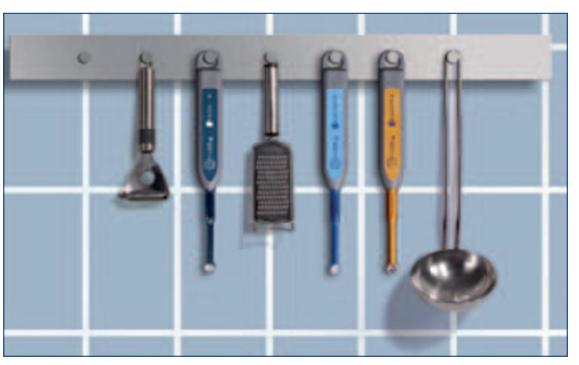

\section{Gain full visibility}

Evident's new radiopaque flowable can help if you are having trouble seeing your flowable linings on X-rays. Accolade SRO helps you gain full visibility of that all-important margin.

This highly thixotropic flowable composite adapts readily without slumping, has exceptional strength and is ideal as a lining material when combined with bonding systems such as Prelude. It can also be used for restorations and has good aesthetics with polishability. It is available in a number of shades supplied in $5 \mathrm{~g}$ syringes.

Reader response number 54 


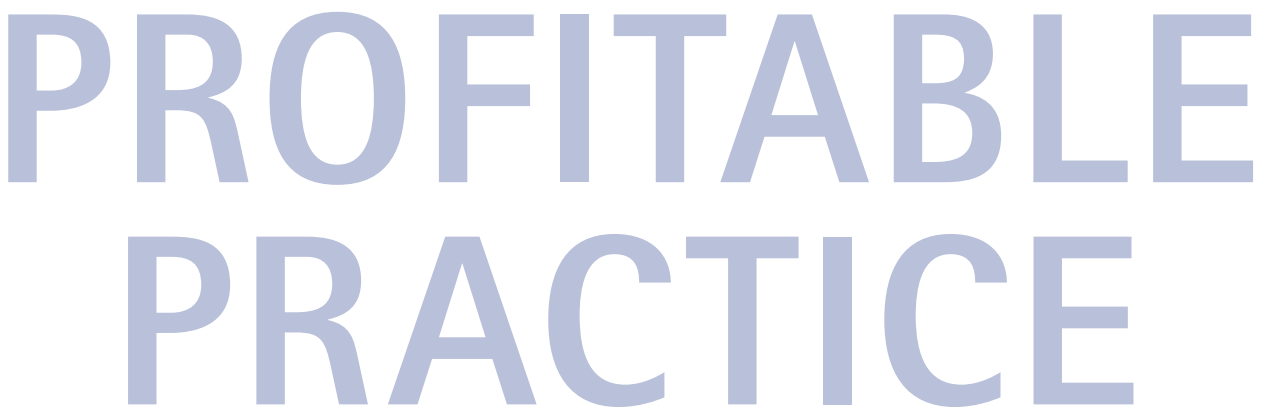

\section{Scheme offers product discounts}

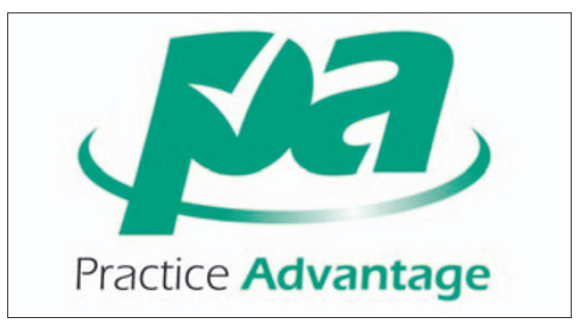

Denplan members and their practice teams are set to benefit from a wide range of discounts on quality products and services with the launch of its new Practice Advantage scheme.

The scheme will provide exclusive offers from dental, lifestyle and consumer companies that can be utilised by both Denplan dentists and all members of their practice teams. Offers have been agreed with companies including Henry Schein, The AA, Orange and Virgin Wines.

The scheme is available via the Denplan member portal at www.denplan. net to help ensure that all information is up-to-date and new offers are available to practices as soon as they have been agreed. To register to use the Denplan member portal and access Practice Advantage, members should contact their Denplan practice support advisor on free phone 08003283223.

Reader response number 56

\section{High quality implant}

3dee Loans allow you to offer all of your patients the highest quality implant treatments. The anxiety of possibly not being paid and the concerns about the patient agreeing to a treatment beyond their means are relieved. 3dee enables patients to spread the cost of their dental treatment, over an

\section{Flexible payments}

The Dental Maintenance Plan (DMP) provides a flexible dental payment plan for private patients and will smoothly facilitate the transition from NHS dentistry or existing capitation schemes.

Designed by dentists for dentists, it launched some years ago as an independent capitation scheme incorporating worldwide accident and emergency insurance cover. The plan features no charge for initial meetings, with practice training and ongoing support.

Reader response number 55

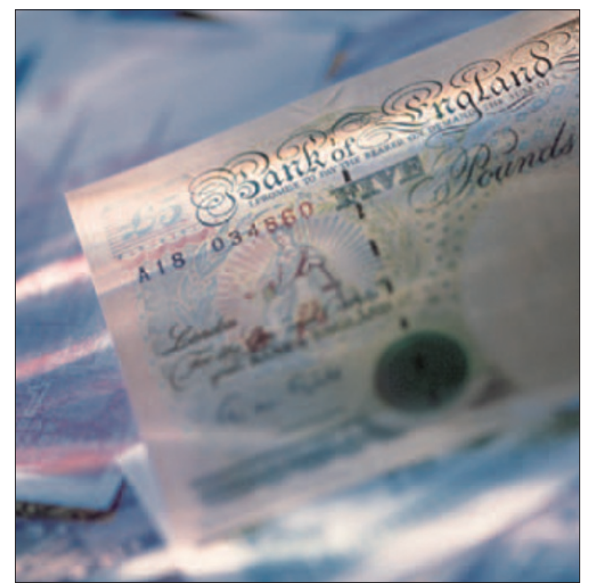

\section{Help for denture-wearing patients}

Straumann have a full range of patient education and dental implant information leaflets to help practitioners explain the benefits of treatment to patients who

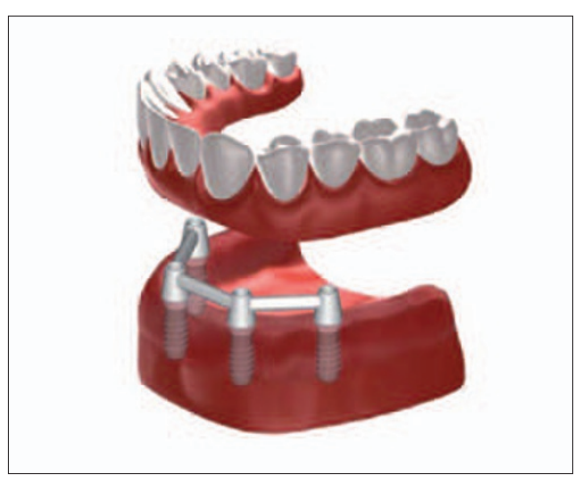

wear or require dentures. Free copies of this information can be obtained by contacting Straumann on 01293651230 or visiting www.straumann.com.

The company recognise that wearing full dentures can lead to many functional problems, as well as unfavourable aesthetic, psychological and social changes in patients. It adds that collectively this group have a disposable income of £175 billion and possess 80\% of all private wealth in the UK and that providing these patients with well fitting, aesthetic dentures secured with implants improves patients' well being and encourages practice growth.

Reader response number $\mathbf{5 7}$ agreed period of up to five years.

The loans minimise risk to the practice, offer competitive interest rates and an interest free option, increase profits and deliver immediate, upfront payment. The company offers full in-house training for the whole practice team and provides all the necessary promotional material and documentation.

Reader response number 58

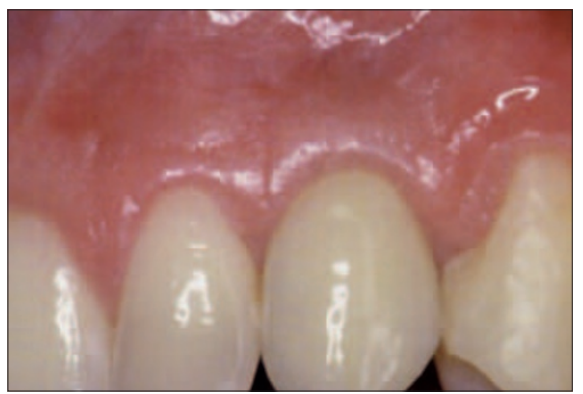




\section{Manage your money}

Dentists worried that overheads are too high and that the essential, everyday expenses of running the practice such as equipment, consumables and even the electricity bill, can sometimes seem to be excessive may find money4dentists can help them regain control.

Your practice could be entitled to offset many more of these expenses against your income than you are currently claiming, making savings which

\section{Market your private dentures}

To help you market your private dentures, Myerson, suppliers of realistic private denture teeth, offer a marketing pack free of charge. The pack includes a shade guide, before and after glossy photographs laminated on card, patient brochures and a mould chart.

To help you to personalise your patients' dentures take a look at Myerson's Living Mould Guide. With actual samples of each of the upper anterior teeth you will be able to exactly match not only the shade of the natural teeth but you will also see and be able to show

\section{Pay as you go plan}

The new Registration and Recall (RetR) plan from DMP is a simple registration system for private patients who prefer to 'pay as they go' and does not commit either you or your patients long term. Patients also receive comprehensive, supplementary insurance cover.

Your patient pays £19.50 per annum for the R\&R plan and at the same time you earn $€ 4$ for each patient that joins or renews their policy. Your patients

\section{Specialist sales}

Frank Taylor \&t Associates (FTA) are specialists in the sale of dental practices and maintain a register of dentists seeking to establish their own practice, and match prospective purchasers with their ideal practice. In many cases discretion is paramount, and FTA has procedures in place to market the practice to only serious candidates with access to adequate finance, eliminating voyeurs with no intention of proceeding.

The Company's experience enables accurate valuations and competent and comprehensive negotiations with all could then be invested back into the business.

Independent specialist advisors for dentists, money4dentists believe that many dentists neglect to claim tax relief on a huge range of qualifying expenses. While the final decision on whether an expense is tax deductible always rests with HM Revenue \&t Customs, money4 dentists is able to offer advice and practical money-saving financial guidance to the dental profession.

Reader response number 59

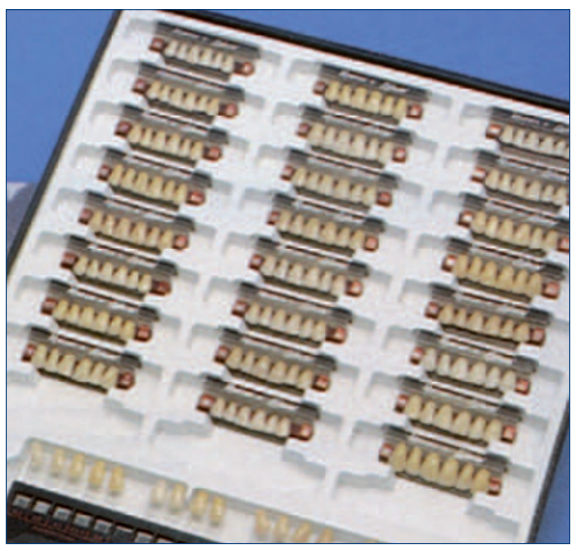

your patients the best match in terms of texture and translucency.

Reader response number $\mathbf{6 0}$

benefit from full emergency cover, including emergency holiday cover as well as accident cover.

In the case of an emergency or accident your patients contact DMP directly and their experienced team will take care of all claims on your behalf. All that is required from you and the patient is an annual examination to ensure that your patient requires no foreseeable treatment in the following 12 months; they can then sign up to the R\&R Plan straight away.

Reader response number 61

interested parties to create a smooth progression to a satisfactory conclusion.

Business sale transactions are notoriously stressful. FTA is able to relieve much of the anxiety inherent in a practice transfer for both buyers and sellers through its established associations with specialist, reputable legal advisers and sources of finance. In the event of an agreed sale failing to complete, FTA retains details of underbidders to ensure a prompt transfer renewal. Throughout the entire process, an FTA consultant is always available to offer advice and guide the seller through every step.

Reader response numbers 62

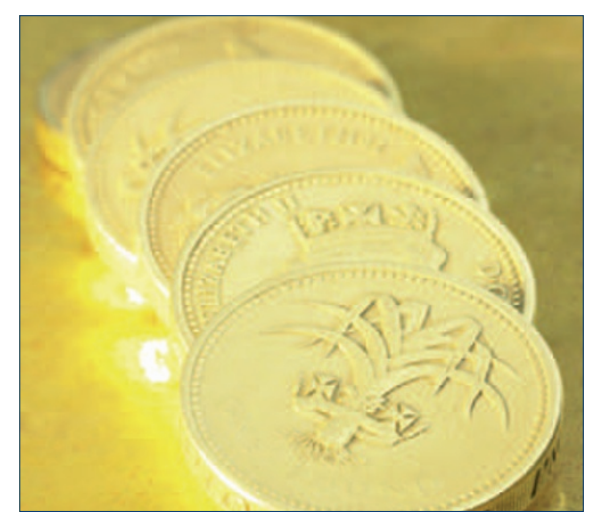

\section{Specialist broker}

The Loan Hunter is a specialist dental loan broker. Experts in the world of commercial finance, they source the best deals available for you with the lowest interest rate at no cost.

Whether you want a loan for practice purchase and practice development, or just to exploit lower interest rates, Loan Hunter uses specialist lenders together with its transparent way of working, giving you access to expert bankers without any catches, charges or tie-ins.

The company has an exceptional track record for arranging large, unsecured loans and as part of the Loan Hunter suite of services, can discuss debt consolidation or improving the terms of an existing loan.

Reader response number 63

\section{The right cover}

On average each year 1,600 members of Dentists' Provident are affected by an accident or illness, of whom around 200 may not ever return to work and may require financial assistance and support until they reach retirement age.

With assets in excess of $£ 150$ million, Dentists' Provident is able to offer these dentists replacement income and financial peace of mind. As a provider of income protection insurance to dentists, it was formed by dentists for dentists. It is the only organisation in the country that provides income protection benefits exclusively to dentists and has done so for approaching 100 years.

Dentists' Provident advises that attention to detail is vital. Modern dentistry plays host to a range of different contracts offering different levels of sickness and accident cover.

Reader response numbers 64 